\title{
Simulasi Pemodelan Sistem Eksitasi Statis pada Generator Sinkron terhadap Perubahan Beban
}

\author{
Hastuti Azis ${ }^{1}$; Pawenary²; Meyhart Torsna Bangkit Sitorus ${ }^{3}$ \\ ${ }^{1,2,3}$ Sekolah Tinggi Teknik PLN \\ ${ }^{1}$ hastuti.sttpln@gmail.com
}

\begin{abstract}
Excitation system is one of the most important parts of synchronous generators, where the system functions to provide dc power to the field generator coil. Iin this study, a static excitation system consisting of transformers and connected thyristors in bridge configuration has been implemented in synchronous machines that operate as 206,1 mva capacity generators, 16,5 $\mathrm{kv}$ using the help of matlab simulink $r 2017 b$ software. By adjusting the load given to the generator, variations in excitation currents can affect the amount of output voltage generated by the generator so that it can increase and decrease the induced voltage. In full load conditions, namely $p=175 \mathrm{mw}, q=100$ mvar, the results of the study show that when the simulation is run at alpha $0^{\circ}$, it is known that the average value of dc voltage is 496,4 v, excitation current is 1057 and voltage generator output has increased beyond its nominal voltage of $16,72 \mathrm{kv}$. in this case, to maintain the terminal voltage, the excitation current must be reduced by increasing the angle of shooting of the thyristor to an alpha angle of $45^{\circ}$, so that the average dc voltage can be reduced to 479,3v, as well as the excitation current to 985,9 a. the generator output voltage at the alpha $45^{\circ}$ angle is obtained according to its nominal value of $1, .5 \mathrm{kv}$.
\end{abstract}

Keywords: synchronous generator, static excitation system, excitation current, output voltage

\begin{abstract}
ABSTRAK
Sistem eksitasi statis yang terdiri dari transformator dan thyristor terhubung dalam konfigurasi jembatan telah diimplementasikan dalam mesin sinkron yang beroperasi sebagai generator berkapasitas 206,1 MVA,16,5 kV dengan menggunakan bantuan perangkat lunak MATLAB Simulink $R 2017 b$. Dengan menyesuaikan beban yang diberikan pada generator, variasi arus eksitasi dapat mempengaruhi besarnya tegangan keluaran yang dihasilkan oleh generator sehingga dapat menaikkan dan menurunkan tegangan induksi. Dalam kondisi beban penuh yaitu $P=175 \mathrm{MW}, Q=100$ $M V A R$, hasil penelitian menunjukkan bahwa ketika simulasi dijalankan pada sudut alfa $0^{\circ}$, diketahui bahwa nilai rata-rata tegangan DC diperoleh sebesar 496,4 V, arus eksitasi sebesar 1057 A dan tegangan keluaran generator telah meningkat melampaui tegangan nominalnya yaitu sebesar 16,72 $k V$. Dalam hal ini, untuk mempertahankan tegangan terminal maka arus eksitasi harus dikurangi yaitu dengan meningkatkan sudut penembakkan thyristor menjadi sudut alfa $45^{\circ}$, sehingga nilai rata-rata tegangan DC dapat berkurang menjadi 479,3 V, begitu juga arus eksitasi menjadi 985,9 A. Tegangan keluaran generator pada sudut alfa $45^{\circ}$ diperoleh sesuai dengan nilai nominalnya yaitu $16,5 \mathrm{kV}$.
\end{abstract}

Kata kunci: Generator sinkron, sistem eksitasi statis, arus eksitasi, tegangan keluaran 


\section{PENDAHULUAN}

Berdasarkan catu daya yang digunakan sebagai sumber eksitasi, model sistem eksitasi dapat diklasifikasikan menjadi tiga kelompok besar yaitu sistem eksitasi DC, sistem eksitasi AC dan sistem eksitasi statis. Sistem eksitasi merupakan salah satu bagian terpenting dari generator. Sistem eksitasi dimaksudkan untuk menyediakan arus searah ke kumparan medan generator. Selain itu, sistem eksitasi juga bertanggung jawab untuk fungsi kontrol dan proteksi dari sistem tenaga. Sebagai unit kontrol penting generator, sistem eksitasi memiliki dampak langsung pada stabilitas dan keandalan generator.

Dalam penelitian ini akan dibahas tentang sistem eksitasi statis yang akan diimplementasikan dalam generator sinkron. Sistem eksitasi statis diracang untuk memenuhi semua mode operasi generator berkapasitas besar. Salah satu pembangkit listrik di Indonesia yang menerapkan sistem eksitasi statis adalah PLTA Saguling, Jawa Barat. PLTA ini menghasilkan daya sebesar 700,72 MW yang terdiri dari empat unit generator, dimana masing-masing generator mempunyai keluaran daya sebesar 175,18 MW. Dengan diperolehnya keluaran daya yang cukup besar, maka perubahan beban yang terjadi pada pembangkit listrik dapat menyebabkan fluktuasi tegangan keluaran generator, dimana hal ini akan berdampak pada ketidakstabilan sistem secara keseluruhan. Faktor yang mempengaruhi dalam proses pembangkitan energi listrik oleh generator dikarenakan adanya perubahan kebutuhan daya reaktif pada sisi beban, dimana kenaikan daya reaktif ini dapat menyebabkan penurunan besarnya tegangan terminal. Dalam rangka menciptakan kestabilan tegangan yang dihasilkan oleh generator, maka dalam penelitian ini sistem eksitasi statis pada generator sinkron dimodelkan dan disimulasikan dengan menggunakan MATLAB Simulink R2017b yang nantinya dapat diketahui besarnya arus eksitasi dan tegangan keluaran generator yang dipengaruhi oleh perubahan beban.

Tujuan penelitian ini adalah untuk mengimplementasikan sistem eksitasi statis pada generator sinkron dan menjaga tegangan keluaran generator tetap stabil serta mengetahui pengaruh perubahan beban daya reaktif terhadap arus eksitasi dan tegangan keluaran generator dengan menggunakan MATLAB Simulink R2017b.

Manfaat penelitian ini adalah untuk mengetahui besarnya arus eksitasi dan tegangan keluaran generator terhadap perubahan beban daya reaktif dalam rangka menciptakan kestabilan tegangan yang dihasilkan oleh generator.

\section{METODE/PERANCANGAN PENELITIAN}

\subsection{Data Penelitian}

\subsubsection{Data Teknis Generator Sinkron}

Generator sinkron yang digunakan sebagai referensi dalam penelitian ini adalah generator sinkron PLTA Saguling, Jawa Barat. Berikut merupakan data teknis generator sinkron seperti yang ditunjukkan pada Tabel 1.

Tabel 1. Data Teknis Generator Sinkron

\begin{tabular}{|l|c|c|}
\hline \multicolumn{1}{|c|}{ Deskripsi } & Parameter & Nilai \\
\hline Daya nominal & $P_{n}$ & $206,1 \mathrm{MVA}$ \\
\hline Tegangan nominal & $V_{n}$ & $16,5 \mathrm{kV}$ \\
\hline Frekuensi & $f$ & $50 \mathrm{~Hz}$ \\
\hline Jumlah kutub & $P$ & 18 \\
\hline Rated current & $I_{a}$ & $7212 \mathrm{~A}$ \\
\hline
\end{tabular}




\begin{tabular}{|l|c|c|}
\hline Maximum field voltage & $V_{f}$ & $500 \mathrm{~V}$ \\
\hline Nominal field current & Ifn & $645 \mathrm{~A}$ \\
\hline Field current at full load & Ifload & $1180 \mathrm{~A}$ \\
\hline Synchoronous reactance & $X_{s}$ & $1,32 \Omega$ \\
\hline
\end{tabular}

\subsubsection{Parameter Model Sistem Eksitasi Statis}

Representasi parameter model selanjutnya adalah karakteristik sistem eksitasi. Berikut merupakan parameter model sistem eksitasi statis yang diperoleh dari PLTA Saguling seperti yang ditunjukkan pada Tabel 2.

Tabel 2. Parameter Model Sistem Eksitasi Statis

\begin{tabular}{|l|c|}
\hline \multicolumn{1}{|c|}{ Parameter } & Nilai \\
\hline Input source & 16,5 \\
& $\mathrm{kV}, 3$ \\
& phase \\
\hline Daya nominal transformator & 850 \\
& $\mathrm{kVA}$ \\
\hline Transformator primer & 16,5 \\
& $\mathrm{kV}$ \\
\hline Transformator sekunder & $420 \mathrm{~V}$ \\
\hline Jembatan penyearah daya & 3 arms \\
\hline Field resistance & $1 \Omega$ \\
\hline Field inductance & 4,20 \\
& $\mathrm{mH}$ \\
\hline
\end{tabular}

\subsubsection{Perancangan Model Simulasi}

Seluruh sistem akan dimodelkan dan disimulasikan dengan menggunakan software MATLAB Simulink R2017b. Secara garis besar, sistem dapat dijelaskan seperti yang ditunjukkan pada Gambar 1.

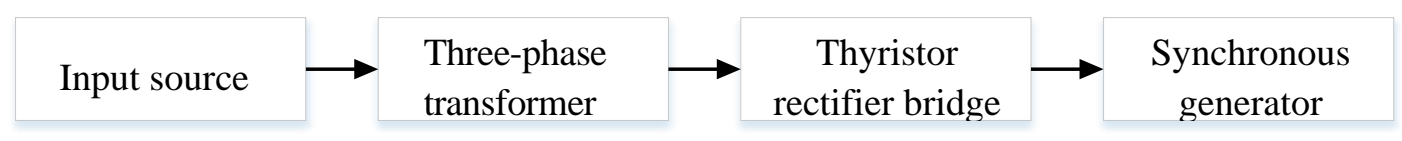

Gambar 1. Blok Diagram Penelitian

Penjelasan blok diagram penelitian berdasarkan Gambar 1 adalah:

1. Input source sebagai sumber eksitasi yang merupakan sumber tegangan tiga fase $(16,5 \mathrm{kV}$, $50 \mathrm{~Hz}$ )

2. Transformator digunakan untuk menyesuaikan tegangan output $16,5 \mathrm{kV}$ dari input source ke jembatan penyearah daya.

3. Jembatan penyearah daya adalah konverter penuh dan enam pulsa generator (thyristor) tersinkronisasi. Jembatan penyearah yang diterapkan berfungsi untuk menyearahkan tegangan AC dari keluaran transformator menjadi tegangan DC yang kemudian akan diumpankan ke kumparan medan generator sebagai catu daya sistem eksitasi. 
4. Generator sinkron merupakan mesin listrik berputar yang menghasilkan tegangan bolakbalik terhadap sistem.

\subsubsection{Implementasi Blok Model pada MATLAB Simulink R2017b}

Berikut akan dijelaskan beberapa model blok utama yang akan diimplementasikan dalam proses simulasi pemodelan sistem eksitasi statis pada generator sinkron dengan menggunakan MATLAB Simulink R2017b.

\section{a. Mesin Sinkron}

Blok mesin sinkron dapat beroperasi dalam mode generator atau motor. Mode pengoperasian ditentukan oleh tanda daya mekanis (positif untuk mode generator, negatif untuk mode motor). Dalam penelitian ini, blok mesin sinkron beroperasi dalam mode generator.

\section{b. Three-Phase Voltage Source}

Blok three-phase voltage source merupakan sumber tegangan tiga fase sebagai sumber statis dari sistem eksitasi yang akan diimplementasikan pada generator sinkron.

\section{c. Three-Phase Transformer}

Blok three-phase transformer mengimplementasikan transfomator tiga fase dengan koneksi gulungan yang dapat dikonfigurasi. Transformator yang diterapkan dalam penelitian adalah transformator step-down dengan satu gulungan primer dalam mode bintang (Y) dan satu gulungan sekunder dalam mode delta $(\Delta)$ yang berfungsi untuk menyesuaikan tegangan dari input source ke jembatan penyearah daya.

\section{d. Pulse Generator (Thyristor, 6-Pulse)}

Blok pulse generator (thyristor, 6-pulse) digunakan untuk menembak thyristor dan mengontrol konverter thyristor dari jembatan penyearah daya.

\section{e. Jembatan Penyearah Daya}

Blok jembatan penyearah daya mengimplementasikan jembatan perangkat elektronika daya yang menerapkan konverter daya tiga fase untuk menyearahkan AC ke DC. Jenis perangkat elektronika daya yang digunakan di jembatan adalah thyristors.

\section{f. RLC Parallel Load}

Blok RLC parallel load mengimplementasikan beban seimbang tiga fase. Blok ini terhubung ke generator melalui blok model pengukuran tegangan dan arus generator tiga fase.

\section{g. Powergui}

Blok powergui merupakan sebuah antarmuka grafis yang berguna untuk menyelesaikan sebuah pemodelan atau rangkaian yang telah dibuat dengan berbagai metode yang telah disediakan. Selain itu blok ini dapat menyetel jenis simulasi, parameter simulasi dan preferensi. Jenis metode yang diterapkan dalam penelitian ini dengan menggunakan metode continuous (default) yaitu berupa variable-step solver otomatis dari simulink. 


\section{HASIL DAN PEMBAHASAN}

\subsection{Deskripsi Model Simulasi}

Seluruh sistem telah dimodelkan dengan menggunakan perangkat lunak MATLAB Simulink R2017b seperti yang ditunjukkan pada Gambar 2, dimana sistem ini terdiri dari generator sinkron tiga fase dengan nilai nominal 206,1 MVA, 16,5 kV dihubungkan ke beban dengan jenis sistem eksitasi yang diterapkan adalah sistem eksitasi statis.

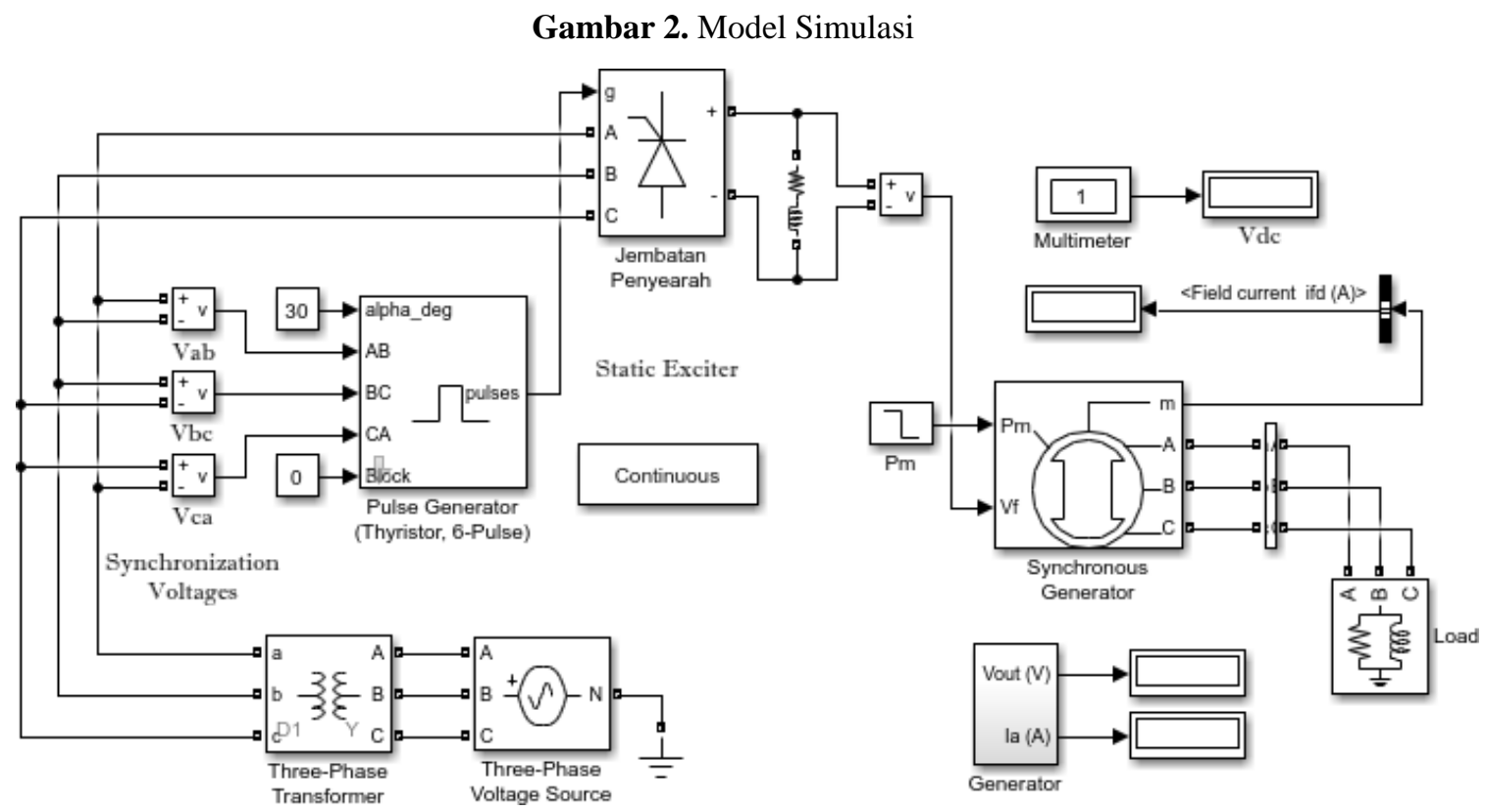

Fungsi dasar dari setiap sistem eksitasi adalah untuk menyediakan sumber DC ke kumparan medan generator sinkron. Sistem eksitasi mengontrol dan melindungi fungsi-fungsi penting dari sistem tenaga untuk operasi dan kinerja yang optimal. Fungsi kontrol termasuk kontrol tegangan generator dan peningkatan stabilitas sistem. Fungsi pelindung memastikan bahwa batas kemampuan mesin sinkron, sistem eksitasi dan peralatan lainnya tidak terlampaui.

Dalam sistem eksitasi yang direalisasikan, sumber daya untuk menyediakan eksitasi berasal dari sumber tegangan tiga fase yang terhubung melalui transformator. Transformator yang dimaksud adalah transformator step-down dengan satu gulungan primer dalam mode bintang $(\mathrm{Y})$ dan satu gulungan sekunder dalam mode delta $(\Delta)$ yang berfungsi untuk menurunkan tegangan dari $16,5 \mathrm{kV}$ menjadi 420 VAC.

\subsection{Hasil Simulasi}

\subsubsection{Hasil Simulasi Pemodelan Sistem Eksitasi Statis}

Perlu diketahui bahwa nilai tegangan nominal generator sinkron dalam penelitian ini adalah $16,5 \mathrm{kV}$. Untuk menentukan nilai rata-rata tegangan DC dalam pemodelan ini dilakukan oleh blok multimeter dimana blok ini menghitung tegangan yang ditentukan dalam parameter perhitungan dalam model yang telah dibuat.

Simulasi pertama dalam pemodelan sistem eksitasi statis dijalankan dengan sudut alfa $0^{\circ}$ (blok konstan yang terhubung pada input satu dari blok pulse generator (thyristor, 6-pulse) diatur nilainya ke 0) dan beban yang diberikan pada generator dalam kondisi beban penuh yaitu sebesar $\mathrm{P}=175$ MW, Q = 100 MVAR. Hasil penelitian menunjukkan bahwa tegangan keluaran generator telah 
meningkat melampaui tegangan nominalnya yaitu sebesar $16,72 \mathrm{kV}$, dimana nilai rata-rata tegangan DC yang menjadi input tegangan medan $\left(V_{f}\right)$ dari blok generator sinkron diperoleh sebesar 496,4 V dan arus eksitasi diperoleh sebesar $1057 \mathrm{~A}$.

Dalam hal ini, untuk mempertahankan tegangan terminal sesuai dengan nilai nominalnya maka arus eksitasi harus dikurangi yaitu dengan meningkatkan sudut penembakkan thyristor yang menjadi sudut alfa $45^{\circ}$ sehingga nilai rata-rata tegangan DC dapat berkurang menjadi $479,3 \mathrm{~V}$, begitu juga dengan arus eksitasinya menjadi 985,9 A. Tegangan keluaran pada sudut alfa $45^{\circ}$ diperoleh sesuai dengan nilai nominalnya yaitu $16,5 \mathrm{kV}$. Gambar 3 menunjukkan hasil keluaran gelombang tegangan $\mathrm{DC}\left(V_{d c}\right)$ dari blok jembatan penyearah daya.

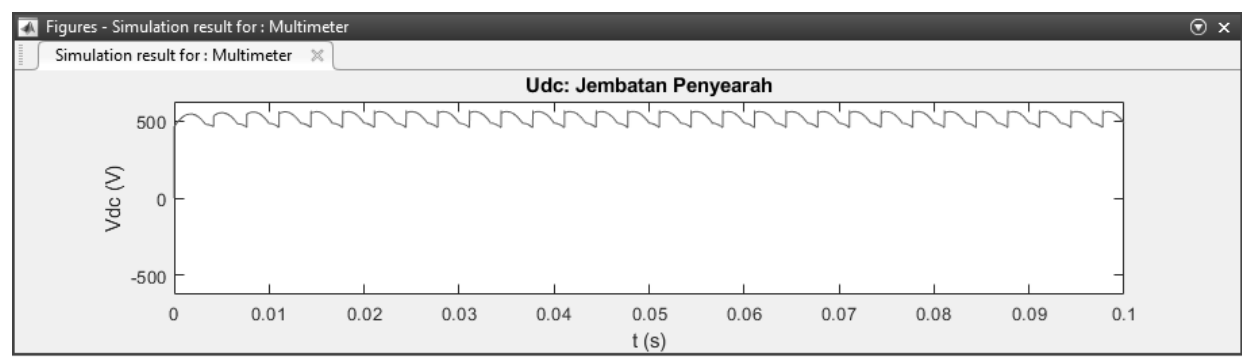

Gambar 3. Hasil Keluaran Gelombang Tegangan DC

Pengaturan tegangan generator dilakukan dengan mengontrol nilai tegangan medan dari keluaran jembatan penyearah. Perbandingan hasil simulasi berdasarkan sudut alfa ditunjukkan pada Tabel 3.

Tabel 3. Perbandingan Hasil Simulasi Berdasarkan Sudut Alfa

\begin{tabular}{|c|c|c|c|}
\hline $\begin{array}{c}\text { Sudut } \\
\text { alfa }\end{array}$ & $\begin{array}{c}\text { Tegangan medan } \\
(\mathrm{V})\end{array}$ & Arus eksitasi (A) & $\begin{array}{c}\text { Tegangan } \\
\text { keluaran }(\mathrm{kV})\end{array}$ \\
\hline $0^{\circ}$ & 496,4 & 1057 & 16,72 \\
\hline $10^{\circ}$ & 490,7 & 1026 & 16,65 \\
\hline $20^{\circ}$ & 485,1 & 1013 & 16,6 \\
\hline $30^{\circ}$ & 483,4 & 997,4 & 16,56 \\
\hline $40^{\circ}$ & 480,9 & 990,2 & 16,52 \\
\hline $45^{\circ}$ & 479,3 & 985,9 & 16,5 \\
\hline $50^{\circ}$ & 477,5 & 981,3 & 16,47 \\
\hline $60^{\circ}$ & 474,3 & 953,6 & 16,32 \\
\hline $70^{\circ}$ & 462,1 & 938,2 & 16,22 \\
\hline $80^{\circ}$ & 460,9 & 937,6 & 16,21 \\
\hline $90^{\circ}$ & 440,2 & 914,4 & 16 \\
\hline
\end{tabular}

Berdasarkan Tabel 3, bahwa dalam kondisi beban $\mathrm{P}=175 \mathrm{MW}, \mathrm{Q}=100$ MVAR pengaturan nilai sudut penembakkan thyristor yang tepat untuk memperoleh tegangan generator berada pada nilai nominalnya yaitu pada sudut alfa $45^{\circ}$. 


\subsubsection{Hasil Simulasi Pengaruh Perubahan Beban Daya Reaktif (Induktif)}

Hasil simulasi pemodelan sistem eksitasi statis pada generator sinkron selanjutnya yaitu dengan menyesuaikan beban yang diberikan pada generator sehingga nantinya dapat diketahui besarnya arus eksitasi $\left(I_{f d}\right)$ yang dapat mempengaruhi besarnya tegangan keluaran generator $\left(V_{\text {out }}\right)$ terhadap perubahan beban.

Simulasi pengaruh perubahan beban pada generator yang dilakukan dalam penelitian ini adalah hanya mengubah nilai beban daya reaktif yang diperoleh dari hasil percobaan dan untuk nilai beban daya aktif ditetapkan sama yaitu sebesar $\mathrm{P}=175$ MW. Sudut penembakkan thyristor ditetapkan pada sudut alfa $30^{\circ}$. Hasil data pengujian perubahan beban daya reaktif (induktif) ditunjukkan pada Tabel 4.

Tabel 4. Hasil Data Pengujian Perubahan Beban Daya Reaktif (Induktif)

\begin{tabular}{|c|c|c|c|c|c|}
\hline \multirow{3}{*}{$\begin{array}{c}\text { Data } \\
\text { ke- }\end{array}$} & \multicolumn{4}{|c|}{ Generator } & \multirow{3}{*}{$\frac{\text { Arus eksitasi }}{\text { A }}$} \\
\hline & \multicolumn{2}{|c|}{ Beban } & \multirow{2}{*}{$\begin{array}{c}\text { Arus } \\
\text { A }\end{array}$} & \multirow{2}{*}{$\frac{\text { Tegangan }}{\mathrm{Kv}}$} & \\
\hline & MW & MVAR & & & \\
\hline 1. & 175 & 10 & 6211 & 16,54 & 770,2 \\
\hline 2. & 175 & 15 & 6252 & 16,5 & 783,3 \\
\hline 3. & 175 & 20 & 6301 & 16,46 & 796,1 \\
\hline 4. & 175 & 25 & 6358 & 16,42 & 808,7 \\
\hline 5. & 175 & 30 & 6422 & 16,38 & 820,9 \\
\hline 6. & 175 & 35 & 6490 & 16,34 & 832,7 \\
\hline 7. & 175 & 40 & 6561 & 16,3 & 844,1 \\
\hline 8. & 175 & 45 & 6634 & 16,26 & 855 \\
\hline 9. & 175 & 50 & 6706 & 16,21 & 866,5 \\
\hline 10. & 175 & 55 & 6778 & 16,17 & 875,5 \\
\hline
\end{tabular}

Berdasarkan Tabel 4, pengujian pertama yang dilakukan dalam simulasi adalah pada saat beban daya reaktif (induktif) $\mathrm{Q}=10 \mathrm{MVAR}$, arus eksitasi diperoleh sebesar 770,2 A dan tegangan keluaran generator diperoleh sebesar $16,54 \mathrm{kV}$.

\subsubsection{Hasil Simulasi Pengaruh Perubahan Beban Daya Reaktif (Kapasitif)}

Berikut merupakan hasil data pengujian perubahan beban daya reaktif (kapasitif) seperti yang ditunjukkan pada Tabel 5, dan untuk pengaturan sudut penembakkan thyristor ditetapkan pada sudut alfa $30^{\circ}$.

Tabel 5. Hasil Data Pengujian Perubahan Beban Daya Reaktif (Kapasitif)

\begin{tabular}{|c|c|c|c|c|c|}
\hline \multirow{3}{*}{$\begin{array}{c}\text { Data } \\
\text { ke- }\end{array}$} & \multicolumn{4}{|c|}{ Generator } & \multirow{3}{*}{$\frac{\text { Arus eksitasi }}{\text { A }}$} \\
\hline & \multicolumn{2}{|c|}{ Beban } & \multirow{2}{*}{$\frac{\text { Arus }}{\mathrm{A}}$} & \multirow{2}{*}{$\frac{\text { Tegangan }}{\mathrm{kV}}$} & \\
\hline & MW & MVAR & & & \\
\hline 1. & 175 & 10 & 6216 & 16,72 & 725,8 \\
\hline ana2. & 175 & 15 & 6250 & 16,78 & 716,9 \\
\hline 3. & 175 & 20 & 6289 & 16,84 & 708 \\
\hline 4. & 175 & 25 & 6333 & 16,89 & 699 \\
\hline 5. & 175 & 30 & 6383 & 16,95 & 690 \\
\hline
\end{tabular}


Berdasarkan Tabel 5, kenaikan beban daya reaktif (kapasitif) dapat menyebabkan kenaikan tegangan keluaran generator.

\subsubsection{Analisis Perhitungan Variasi Arus Eksitasi Terhadap Tegangan Induksi}

Telah dijelaskan sebelumnya bahwa dengan menyesuaikan beban yang diberikan pada generator, maka variasi arus eksitasi dapat meningkatkan dan menurunkan tegangan induksi $\left(E_{a}\right)$. Berdasarkan data standar generator sinkron yang ditunjukkan pada Tabel 1, diketahui bahwa reaktansi sinkron $X_{S}=1,32 \Omega$. Dari hasil data pengujian perubahan beban daya reaktif (induktif) dari simulasi pemodelan sistem eksitasi statis, tegangan yang dibangkitkan generator dapat dihitung sebagai berikut:

$$
\begin{aligned}
& =16420+(\mathrm{j} 1,32 \times 6358) \\
& =18440,48 \angle 27,07^{\circ} \\
& =18,440 \mathrm{kV}
\end{aligned}
$$

Sesuai perhitungan berdasarkan Persamaan (1), maka hasil perhitungan tegangan induksi yang diperoleh dari hasil simulasi pengaruh perubahan beban daya reaktif (induktif) ditunjukkan pada

\begin{tabular}{|c|c|c|c|c|c|c|}
\hline \multirow{2}{*}{$\begin{array}{l}\text { Data } \\
\text { ke- }\end{array}$} & \multicolumn{2}{|c|}{ Beban } & \multirow{2}{*}{$I_{a}(\mathrm{~A})$} & \multirow{2}{*}{$V_{\text {out }}(\mathbf{k V})$} & \multirow{2}{*}{$I_{f d}(\mathbf{A})$} & \multirow{2}{*}{$E_{a}(\mathbf{k V})$} \\
\hline & MW & MVAR & & & & \\
\hline 1. & 175 & 10 & 6211 & 16,54 & 770,2 & 18,431 \\
\hline 2. & 175 & 15 & 6252 & 16,5 & 783,3 & 18,433 \\
\hline 3. & 175 & 20 & 6301 & 16,46 & 796,1 & 18,437 \\
\hline 4. & 175 & 25 & 6358 & 16,42 & 808,7 & 18,440 \\
\hline 5. & 175 & 30 & 6422 & 16,38 & 820,9 & 18,443 \\
\hline 6. & 175 & 35 & 6490 & 16,34 & 832,7 & 18,449 \\
\hline 7. & 175 & 40 & 6561 & 16,3 & 844,1 & 18,457 \\
\hline 8. & 175 & 45 & 6634 & 16,26 & 855 & 18,468 \\
\hline 9. & 175 & 50 & 6706 & 16,21 & 866,5 & 18,469 \\
\hline 10. & 175 & 55 & 6778 & 16,17 & 875,5 & 18,480 \\
\hline
\end{tabular}
Tabel 6.

Tabel 6. Hasil Perhitungan Tegangan Induksi

Dalam perhitungan tegangan yang dibangkitkan generator sesuai dengan Tabel 6, dapat diperoleh bahwa semakin besar arus eksitasi $\left(I_{f d}\right)$ maka tegangan induksi $\left(E_{a}\right)$ semakin besar. Kenaikan arus eksitasi ini memiliki peranan yang penting untuk menyesuaikan dan mempertahankan tegangan keluaran generator yang nilainya berubah-ubah. Tegangan keluaran generator yang awalnya sesuai dengan nilai nominalnya pada beban $\mathrm{P}=175 \mathrm{MW}, \mathrm{Q}=15 \mathrm{MVAR}$, kemudian dikarenakan perubahan beban daya reaktif berupa induktif terus meningkat maka tegangan terminal mengalami penurunan, sehingga nilai arus eksitasi semakin besar, begitu juga dengan sebaliknya. Penjelasan tersebut dapat membuktikan bahwa arus eksitasi berguna untuk menjaga kestabilan tegangan terminal generator agar tetap pada batas toleransi dan cenderung konstan meskipun dalam kondisi beban yang sifatnya berubah-ubah. 


\section{KESIMPULAN DAN SARAN}

Berdasarkan hasil dan pembahasan yang telah diperoleh maka kesimpulan dari penelitian simulasi pemodelan sistem eksitasi statis pada generator sinkron terhadap perubahan beban adalah apabila tegangan keluaran generator telah meningkat melampaui tegangan nominalnya, maka arus eksitasi harus dikurangi dengan cara meningkatkan sudut penembakkan thyristor, begitu juga dengan sebaliknya. Kenaikan beban daya reaktif (induktif) dapat menyebabkan tegangan keluaran generator mengalami penurunan sehingga arus eksitasi harus diperbesar. Sedangkan kenaikan beban daya reaktif (kapasitif) dapat menyebabkan tegangan keluaran generator meningkat sehingga arus eksitasi perlu dikurangi. Arus eksitasi berbanding lurus dengan tegangan yang dibangkitkan generator, dimana semakin besar arus eksitasi maka semakin besar juga tegangan yang dibangkitkan generator.

Berdasarkan hasil penelitian yang telah dilaksanakan, saran dalam pengembangan penelitian selanjutnya adalah dalam hal pengoperasian generator perlu diperhatikan kelayakan dari sistem kontrol generator guna memperoleh pengaturan yang tepat bagi generator sehingga kestabilan generator tetap terjaga.

\section{DAFTAR PUSTAKA}

[1] K. S. Z. Jerkovic, Vedrana; Miklosevic, (2010) "Excitation System Models of Synchronous Generator," 28th Int. Conf. Sci. Pract.,.

[2] S. Tsegaye and K. A. Fante, (2016), "Analysis of Synchronous Machine Excitation Systems: Comparative Study,” Int. J. Energy Power Eng., vol. 10, no. 12, pp. 1492-1496.

[3] J. K. Noland and U. Lundin, (2013) "Step Time Response Evaluation of Different Synchronous Generator Excitation Systems," IEEE Int. Energy Conf., pp. 1-7, 2016. I. Ridzki, "Analisis Pengaruh Perubahan Eksitasi Terhadap Daya Reaktif Generator," J. ELTEK, vol. 11, no. 2, pp. 31-41.

[4] I. S. Amien, (2014) "Studi Pengaruh Arus Eksitasi Pada Generator Sinkron Yang Bekerja Paralel Terhadap Perubahan Faktor Daya," SINGUDA ENSIKOM, vol. 7, no. 1, pp. 8-15.

[5] S. Armansyah, (2016) "Pengaruh Penguatan Medan Generator Sinkron Terhadap Tegangan Terminal," J. Tek. Elektro UISU, vol. 1, no. 3, pp. 48-55.

[6] R. G. Terimananda, N. Hariyanto, and Syahrial, (2016) "Studi Pengaturan Arus Eksitasi untuk Mengatur Tegangan Keluaran Generator di PT Indonesia Power UBP Kamojang Unit 2," Tek. Elektro, vol. 4, no. 1, pp. 1-12.

[7] Y. I. Al Mashhadany, F. Amir, and N. Anwer, (2014) "Modeling, Simulation and Analysis of Excitation System for Synchronous Generator," Asian J. Eng. Technol., vol. 02, no. 05, pp. 430-437.

[8] S. Hobi, (2018) "Simulation of a Synchronous Machine Model," Power Syst. Lab.

[9] I. Boldea, (2016) "The Electric Generators Handbook, Synchronous Generators, Second Edition (CRC Press)". Taylor \& Francis Group, LLC.

[10] M. Irmak, E. Guler, N. Ersan, (2016) "PI Controlled Solar Energy Supported Static Excitation System Design and Simulation for Synchronous Generators," ICRERA, vol. 5.

[11] P. Butros, (2011) "Simulations of Rotating Brushless AC Excitation System with Controlled Thyristor Bridge Rectifier for Hydropower Generators," UPTEC, pp. 3-38.

[12] A. K. Datta, M. Dubey, and S. Jain, (2014) "Modelling and Simulation of Static Excitation System in Synchronous Machine Operation," vol. 8, no. 3, pp. 564-569,.

[13] M. Pamungkas and E. Rijanto, (2017) "Modifikasi Topologi Pengendali PID untuk Automatic Voltage Regulator Generator Sinkron," JNTETI, vol. 6, no. 3, pp. 380-385 